Vol. 2, No. 2 (2021):65-81

http://journalsttcipanas.ac.id/index.php/NPTRS/

p-ISSN 2722-9726, e-ISSN 2722-9718

Published by Cipanas Theological Seminary

\title{
Implementasi Arkeologi Alkitabiah (Biblical Archaeology) Dalam Hermeneutik Sebagai Metode Penafsiran Alkitab
}

\author{
Jhon Leonardo Presley Purba, Yonathan Wingit Pramono, Robinson Rimun \\ Sekolah Tinggi Teologi Baptis Indonesia, Semarang \\ jhonpresley@stbi.ac.id, yonathanwingit@stbi.ac.id, robinsonrimun@stbi.ac.id
}

\begin{abstract}
Biblical archaeology has very important roles in the method of hermeneutic interpretation to obtain an accurate, valid, precise and accountable interpretation of the Bible. Through a qualitative approach with a literature study method, this study concludes that biblical archaeology in hermeneutics has the implementations as a tool to reveal the historical context and cultural meaning of a text by understanding the archaeological relationship with the biblical text, as a tool to identify the text to adapt its content to the context of the Ancient Near East through the identification of historical, cultural, social, and religious issues provided by archaeological data, as a tool to build the construction of biblical-archaeological exegesis by combining both of data sources through critical thinking to adjust archaeological data with biblical data, as a tool control for context history and a tool produce more accurate historical information for listeners for more accurate application.
\end{abstract}

Keywords: Hermeneutics; Biblical Archaeology; Interpretation; Biblical Studies; History

\begin{abstract}
Abstrak
Arkeologi alkitabiah dalam metode penafsiran hermeneutik untuk mendapatkan penafsiran Alkitab yang akurat, valid, teliti dan dapat dipertanggungjawabkan sangat penting. Melalui pendekatan kualitatif dengan metode studi literature, penelitian ini
\end{abstract}


Vol. 2, No. 2 (2021):65-81

http://journalsttcipanas.ac.id/index.php/NPTRS/

p-ISSN 2722-9726, e-ISSN 2722-9718

Published by Cipanas Theological Seminary

menyimpulkan bahwa arkeologi alkitabiah dalam hermeneutik memiliki implementasi sebagai alat untuk mengungkap konteks historis dan makna budaya sebuah teks dengan memahami hubungan arkeologi dengan teks Alkitab, sebagai alat untuk mengidentifikasi teks untuk menyesuaikan kontennya dengan konteks Timur Dekat Kuno melalui identifikasi sejarah, budaya, sosial, dan masalah-masalah keagamaan yang disediakan oleh data-data arkeologi, sebagai alat membangun konstruksi eksegesis alkitabiah-arkeologis dengan menggabungkan kedua sumber data tersebut melalui pemikiran kritis untuk menyesuaikan data arkeologi dengan data alkitabiah, sebagai alat kontrol untuk konteks sejarah dan alat menghasilkan informasi historis yang lebih akurat bagi pendengar agar penerapan lebih akurat.

Kata kunci: Hermeneutik; Arkeologi Alkitabiah; Penafsiran; Studi Biblika; Sejarah

\section{Pendahuluan}

Memahami Alkitab dengan tujuan untuk menginterpretasikannya merupakan suatu perkerjaan yang tidak mudah. Hal ini dikarenakan ada perbedaan waktu yang panjang antara masa terjadinya peristiwa-peristiwa sejarah yang tercatat di dalam Alkitab dengan pembaca masa kini. ${ }^{1}$ Selain perbedaan waktu, terdapat juga perbedaan bahasa, budaya, tradisi maupun kebiasaan yang menjadi variabel sulitnya memahami dan menginterpretasikan teks-teks Alkitab. ${ }^{2}$ Namun demikian, Alkitab adalah Firman Allah yang diwahyukan kepada manusia, yang senantiasa relevan sepanjang zaman sebagai dasar keselamatan dan kehidupan iman setiap orang percaya di segala zaman. ${ }^{3}$ Oleh karena itu, usaha untuk memahami dan menginterpretasikan Alkitab sangat penting untuk dilakukan agar prinsip-prinsip kebenaran Alkitab dapat dimengerti untuk

\footnotetext{
${ }^{1}$ Jhon Leonardo Presley Purba and Robinson Rimun, "Kritik Terhadap Metode Tafsir Hermeneutik Pembebasan Terhadap Peristiwa Keluaran Sebagai Suatu Bentuk Pembebasan,” Jurnal Teologi Amreta 4, no. 2 (2021), http://ojs.sttsati.ac.id/index.php/amreta/article/view/54.

2 Zondervan, NIV Cultural Backgrounds Study Bible Bringing to Life the Ancient World of Scripture (Grand Rapids Michigan, USA: Zondervan, 2016), xii.

${ }^{3}$ Donald G. Bloesch, Christian Foundations Holy Scripture Revelation, Inspiration and Interpretation (Illinois, USA: The Paternoster Press, 1994), 47.
} 
Vol. 2, No. 2 (2021):65-81

http://journalsttcipanas.ac.id/index.php/NPTRS/

p-ISSN 2722-9726, e-ISSN 2722-9718

Published by Cipanas Theological Seminary

menjadi pedoman iman dan diaplikasikan dalam kehidupan orang percaya masa kini. ${ }^{4}$ Cara yang umum dilakukan untuk memahami dan menginterpretasikan teks-teks Alkitab adalah melalui usaha penafsiran dengan pendekatan hermeneutik. ${ }^{5}$

Hermeneutik memiliki sejarah yang panjang sebagai suatu pendekatan untuk menginterpretasikan Alkitab dan selain itu juga memiliki kompleksitas yang tinggi. Kompleksitas yang tinggi ini terjadi karena dalam skop hermeneutik, selain bertujuan untuk melakukan eksegesis dan interpretasi terhadap teks-teks Alkitab, hermeneutik juga meliputi tahapan selanjutnya dengan mengajukan pertanyaan-pertanyaan kritis terhadap teks yang sedang dibaca dan dipelajari untuk memahami dan menemukan aplikasi yang relevan dengan masa kini. ${ }^{6}$ Kompleksitas hermeneutik juga tampak dari berbagai disiplin ilmu yang digunakan untuk mengoperasikan hermeneutik mengeksplorasi kondisi dan kriteria agar memastikan interpretasi dapat dipertanggung jawabkan, valid, bermanfaat, dan tepat. Berbagai disiplin ilmu yang digunakan antara lain studi-studi biblika, filsafat, teologi dan studi-studi kepustakaan. ${ }^{7}$

Di sisi lain, penggunaan hasil temuan-temuan arkeologis untuk dijadikan alat dalam penafsiran Alkitab telah berkembang menjadi pendekatan penafsiran baru yang digunakan oleh para ahli dunia Timur Tengah Kuno untuk menafsirkan teks-teks Ibrani kuno atau Alkitab kuno agar dapat lebih tepat dan teliti mendapatkan makna dan arti dari teks-teks tersebut. Hal ini dilakukan karena pada saat bersamaan ditemukan kelemahan para sarjana biblika dalam melakukan penafsiran terutama para sarjana konservatif yang umumnya berkonsentrasi hanya pada teks dengan hasil analisis bernuansa teologis tapi mengabaikan data-data faktual seperti data artifak atau peninggalan-peninggalan arkeologis kuno yang dapat memberikan penjelasan bagaimana suatu peristiwa terjadi. Data-data faktual ini tidak dapat hanya dipandang

\footnotetext{
${ }^{4}$ Zondervan, NIV Cultural Backgrounds Study Bible Bringing to Life the Ancient World of Scripture, xii.

${ }^{5}$ Richard L. Pratt, He Gave Us Scripture: Foundations of Interpretation (Florida, USA: Third Millennium Ministries, 2013), 1.

${ }^{6}$ Merold Blomberg, Craig \& Gaffin, Richard \& Spencer, Scott \& Wall, Robert \& Westphal, Biblical Hermeneutics: Five View (Illinois, USA: Intervarsity Press, 2012), 12.

${ }^{7}$ Ibid., 20.
} 
Vol. 2, No. 2 (2021):65-81

http://journalsttcipanas.ac.id/index.php/NPTRS/

p-ISSN 2722-9726, e-ISSN 2722-9718

Published by Cipanas Theological Seminary

sebagai pelengkap informasi dalam teks-teks biblika. Karena jika hal itu yang dilakukan maka konsekuensinya adalah para ahli konservatif tersebut sebatas memperoleh sejarah mengenai literature "tentang" agama Israel kuno daripada deskripsi dari praktek keagamaan yang "aktual." Konsekuensi lainnya adalah para teolog tersebut lebih cenderung untuk melakukan "idealisasi" atau "spiritulisasi" agama Israel kuno, dari pada memperhatikan praktek kultus aktual yang menjadi perhatian besar dalam pendekatan arkeologis. ${ }^{8}$

Pendekatan arkeologis dalam menafsirkan teks-teks Alkitab telah menjadi suatu disiplin ilmu dalam ranah studi-studi biblika (biblical studies), yang digunakan oleh para penafsir sebagai metode untuk dapat memahami dengan tepat latar belakang dari narasi peristiwa-peristiwa sejarah dalam teks-teks Alkitab dan disiplin ilmu ini disebut biblical archeology atau arkeologi alkitabiah. ${ }^{9}$ Berdasarkan uraian di atas, paper ini dimaksudkan untuk melakukan kajian yang lebih mendalam tentang bagaimana implementasi biblical archaeology atau arkeologi alkitabiah dalam hermeneutik untuk melakukan penafsiran terhadap teks-teks Alkitab yang lebih valid, teliti, tepat dan dapat dipertanggung jawabkan.

\section{Metode}

Paper disajikan dalam bentuk kualitatif deskriptif menggunakan pendekatan studi literatur untuk mengumpulkan dan mengolah data penelitian dari sumber-sumber kepustakaan yaitu buku, e-book dan jurnal-jurnal penelitian terdahulu yang relevan, yang bertujuan menganalisis implementasi arkeologi alkitabiah terhadap hermeneutik sebagai metode penafsiran Alkitab. Sumber-sumber yang digunakan kredible dan valid sehingga dapat dipertanggungjawabkan secara akademik. Data-data kualitatif dari sumber-sumber teori dan informasi kemudian diolah dan dikolaborasikan yang

\footnotetext{
${ }^{8}$ Marthin Steven Lumingkewas, El Dan Yahweh Allah Israel (Osf Prepints, 2020), 9.

${ }^{9}$ Ilan Sharon, "Biblical Archeology," in Encyclopedia of Archaeology, 2008.
} 
Vol. 2, No. 2 (2021):65-81

http://journalsttcipanas.ac.id/index.php/NPTRS/

p-ISSN 2722-9726, e-ISSN 2722-9718

Published by Cipanas Theological Seminary

selanjutnya di uraikan secara sistematis deskriptif dengan tujuan mendapatkan kesimpulan sebagai hasil penelitian. ${ }^{10}$

\section{Hasil dan Pembahasan}

\section{Definisi dan Signifikansi Arkeologi Alkitabiah}

Alkitab dan pesan yang disampaikanya sepenuhnya bergantung kepada sejarah, termasuk kejatuhan manusia ke dalam dosa di taman Eden, janji lahirnya seorang penyelamat dari seorang perawan, penderitaan Kristus, penyaliban Kristus dan kebangkitan Kristus, di mana semua ini merupakan fondasi dari iman kekristenan. Sebagai dasar iman kekristenan, peristiwa-peristiwa tersebut harus dapat dibuktikan valid secara historis. Hal ini penting karena jika gagal dibuktikan secara historis maka seluruh klaim teologis dari peristiwa-peristiwa tersebut akan runtuh dan tidak dapat dipertahankan. Kekristenan dan teologinya sepenuhnya berdasar pada fakta-fakta historis. ${ }^{11}$ Untuk menemukan fakta-fakta historis dan membuktikan kebenaranya harus dilakukan melalui pendekatan interdisipliner yang saling berhubungan antara studi biblika dan arkeologi untuk membuktikan faktualitas peristiwa-peristiwa sejarah yang tercatat di Alkitab, yang kemudian mendukung konstruksi teologis iman kekristenan yang dibangun di atasnya. ${ }^{12}$ Secara historis hubungan studi biblika dan arkeologi dalam penelitian terhadap Palestina atau Tanah Suci (holy land) yang berhubungan dengan peristiwa-peristiwa alkitabiah telah terjadi sejak 1800-an. ${ }^{13}$

Dictionary of Etymolgy mendefinisikan arkeologi sebagai suatu bidang ilmu yang muncul tahun 1837 dengan fokus mempelajari sejarah kuno termasuk manusia, kebiasaan, adat istiadat, dan kehidupan kuno. Kata "arkeologi" berasal dari bahasa Yunani "archaiologia”, dari kata "archaios" yang berarti kuno, purba, dengan akar

\footnotetext{
${ }^{10}$ Sonny Eli Zaluchu, "Metode Penelitian Di Dalam Manuskrip Jurnal Ilmiah Keagamaan," Jurnal Teologi Berita Hidup 3, no. 2 (2021).

${ }^{11}$ Johnson C. Philip and Saneesh Cherian, Biblical Archeology Volume 1 Archeology And The Christian (USA: Philip Communications, 2013), 2-3.

${ }^{12}$ Lucas Partanda Koestoro, “Arkeologi Alkitab Dalam Fungsinya Sebagai Penjelasan Dan Konfirmasi Alkitab,” Berkala Arkeologi Sangkhakala 13, no. 26 (2018).

13 Joe D. Seger and P. R. S. Moorey, "A Century of Biblical Archaeology," Journal of the American Oriental Society 115, no. 4 (1995).
} 
Vol. 2, No. 2 (2021):65-81

http://journalsttcipanas.ac.id/index.php/NPTRS/

p-ISSN 2722-9726, e-ISSN 2722-9718

Published by Cipanas Theological Seminary

kata "arkhe” yang berarti "permulaan”, dan "logos” yang berarti “ilmu'. Dalam bahasa Indonesia arkeologi sering juga disebut "Ilmu Purbakala" atau "kepurbakalaan". ${ }^{14}$ Menurut Holman Illustrated Bible Dictionary, arkeologi adalah ilmu yang mempelajari tentang masa lalu berdasarkan pemulihan, pemeriksaan, dan penjelasan materi sisa-sisa kehidupan, pemikiran, dan aktivitas manusia yang dikoordinasikan dengan ketersediaan informasi tentang lingkungan kuno. ${ }^{15}$ Ringkasnya "arkeologi" dapat dipahami sebagai penelitian atau ilmu yang mempelajari tentang kehidupan dan budaya manusia pada masa lampau dan tempat-tempat kejadian tersebut terjadi. ${ }^{16}$

Melalui ekskavasi pada lokasi tertentu yang terdapat material kuno akan ditemukan peninggalan-peninggalan yang mengandung informasi yang berguna. Arkeologi adalah sumber landasan penelitian sejarah, bukan sebatas disiplin alat bantu sederhana. Data arkeologis merupakan dokumen sejarah pada dirinya sendiri, bukan sekadar gambaran yang mengilustrasikan teks kesejarahan tertulis. Sebagaimana sejarawan, para arkeolog berupaya merekonstruksi kembali tahapan-tahapan proses pembangunan dunia manusia, termasuk manusia sebagai makhluk yang hidup pada suatu periode dan waktu dalam lingkungan sosial tertentu. ${ }^{17}$

Arkeologi yang fokus melakukan ekskavasi dan studi yang berhubungan dengan Alkitab (studi biblika) kemudian memunculkan disiplin ilmu yang lebih spesifik yaitu arkeologi alkitabiah. ${ }^{18}$ Menurut Holman Illustrated Bible Dictionary, arkeologi alkitabiah (biblical archaelogy) adalah suatu disiplin ilmu yang berkembang sejak 1800, yang fokusnya mencari apa yang dapat dipelajari tentang peristiwa-peristiwa yang tercatat dalam Alkitab, karakter, dan ajaran-ajaran dari sumber di luar Alkitab. Ilmu ini berurusan dengan apa yang ditinggalkan peradaban kuno dan tujuannya adalah untuk

\footnotetext{
${ }^{14}$ Robert K Barnhart, Dictionary of Etymology (New York: Wilson Company, 1995), 35.

${ }^{15}$ Chad Brand, Charles Draper, and Archie England, Holman Illustrated Bible Dictionary (Nashville, Tennessee: Holman Bible Publishers, 2003), 220.

${ }^{16}$ Randall Price and Wyne House, Zondervan Handbook of Biblical Archaeology (Grand Rapids Michigan, USA: World of the Bible Ministries, Inc, 2017), 28.

${ }^{17}$ David L. Baker and John J. Bimson, Mari Mengenal Arkeologi Alkitab (Jakarta: BPK Gunung Mulia, 2011), 5-10.

18 Ibid., 10.
} 


\section{The New Perspective in Theology and Religious Studies}

Vol. 2, No. 2 (2021):65-81

http://journalsttcipanas.ac.id/index.php/NPTRS/

p-ISSN 2722-9726, e-ISSN 2722-9718

Published by Cipanas Theological Seminary

memberikan pemahaman yang lebih baik tentang Alkitab itu sendiri. ${ }^{19}$ Senada dengan definisi di atas, Oksana Hrytsiuta mendefinisikan arkeologi alkitabiah sebagai suatu disiplin ilmu yang objek studinya tentang berbagai manifestasi kehidupan manusia zaman dahulu yang tercatat dalam Alkitab khususnya Yahudi kuno yang tercermin dalam Perjanjian Baru maupun Perjanjian Lama, literatur sipil, dan terutama dalam bukti-bukti material sejarah dari zaman kuno. Ini juga mencakup studi tentang material budaya kuno sebagai sumber-sumber alkitabiah. ${ }^{20}$

Arkeologi alkitabiah menjadi begitu signifikan perananya saat ini karena iman kekristenan sepenuhnya bergantung pada faktualitas data-data historis, dan arkeologi alkitabiah menolong kekristenan untuk mempertahankan dasar historis yang tidak terbantahkan dari Alkitab itu sendiri, ${ }^{21}$ melalui penggalian-penggalian yang dilakukan dengan tujuan untuk merekonstruksi sejauh mungkin sejarah dan budaya situs kuno. ${ }^{22}$ Arkeologi alkitabiah juga ditujukan untuk menerangi tokoh-tokoh besar dan peristiwaperistiwa yang membentuk bangsa Israel, melalui upaya menemukan sisa-sisa peninggalan masa lalu bahkan dari peristiwa kehancuran katastropik. ${ }^{23}$ Penemuan arkeologi alkitabiah akan semakin meneguhkan kefaktualan peristiwa-peristiwa yang tercatat di Alkitab, dimana Alkitab itu sendiri juga merupakan dokumen arkeologis dengan kualitas tertinggi. ${ }^{24}$ Arkeologi alkitabiah juga disebut sebagai arkeologi kawasan, tempat dimana peristiwa-peristiwa di dalam Alkitab terjadi. Albright menyebutnya dengan The Archaelogy of Palestine (1951) yang merujuk tentang arkeologi pada periode-periode kritis sejarah Israel. ${ }^{25}$ Daerah-daerah yang khususnya

\footnotetext{
${ }^{19}$ Brand, Draper, and England, Holman Illustrated Bible Dictionary, 220.

${ }^{20}$ Oksana Hrytsiuta, "Development of Studies in Biblical Archaeology in the Kyiv Theological Academy in the Second Half of XIX Century," Materials and studies on archaeology of Sub-Carpathian and Volhynian area 23 (2019).

${ }^{21}$ Philip and Cherian, Biblical Archeology Volume 1 Archeology And The Christian, 10.

22 Brand, Draper, and England, Holman Illustrated Bible Dictionary, 220.

${ }^{23}$ Philip J. King and Lawrence E. Stager, Kehidupan Orang Israel Alkitbiah (Jakarta: BPK Gunung Mulia, 2010), 25.

${ }^{24}$ Gleason L. Archer, New International Encyclopedia Of Bible Difficulties (Zondervan, 2011), 18.

${ }^{25}$ S. Birnbaum, "The Haverford Symposium on Archælogy and the Bible. By W. F. Albright, G. A. Barton, H. J. Cadbury, J. W. Flight A. Goetze, T. J. Meek, J. A. Montgomery, J. A. Wilson, and E. Grant, Editor. Biblical and Kindred Studies, No. 6. Haverford College, Published Jointly with and
} 
Vol. 2, No. 2 (2021):65-81

http://journalsttcipanas.ac.id/index.php/NPTRS/

p-ISSN 2722-9726, e-ISSN 2722-9718

Published by Cipanas Theological Seminary

menjadi fokus arkeologi alkitabiah adalah Kanaan kuno dan daerah sekitarnya. Hari ini kawasan tersebut meliputi negara-negara seperti Israel, Lebanon, Suriah, dan Yordania, termasuk juga wilayah lain seperti Mesir, Yunani, Italia, Siprus, Jazirah Arab, dan wilayah luas yang sekarang diduduki oleh Turki, Irak, dan Iran. ${ }^{26}$

\section{Kompleksitas Hermeneutik Sebagai Metode Penafsiran Alkitab}

Hermeneutik adalah istilah yang bersinonim dengan interpretasi, di mana istilah ini khususnya merujuk pada metode menafsirkan atau menginterpretasikan Alkitab. Steve Bond dalam Holman Illustrated Bible Dictionary mendefinisikan hermeneutik sebagai teori interpretasi Alkitab, di mana tujuan, metode, prinsip dan kriteria evaluasinya digunakan untuk menginterpretasikan atau menafsirkan teks-teks Kitab Suci. ${ }^{27}$ Baker Illustrated Bible Dictionary mendefinisikan hermeneutik sebagai ilmu dan seni interpretasi Alkitab. Aktifitas penafsiran ini dapat digambarkan seperti spiral, di mana pembaca masa kini berusaha untuk memahami konteks dan maksud asli dari teks yang dibaca, kemudian membawa makna tersebut ke konteks masa kini. Proses yang melibatkan istilah-istilah dan prosedur-prosedur yang kompleks dalam hermeneutik dapat membingungkan. ${ }^{28}$ Kata hermeneutik berasal dari kata kerjaYunani 'hermeneuo' yang berarti "mengungkapkan, menjelaskan, menerjemahkan dan menafsirkan atau menginterpretasikan'. Sebagai suatu metode, hermeneutik diperlukan untuk memahami materi-materi biblika yang ditulis antara 2000-3500 tahun yang lalu dan diformulasikan dalam lingkungan dan bahasa yang berbeda dengan dunia modern masa kini. ${ }^{29}$

Ada satu hal penting yang membedakan penafsiran teks biblika dengan teks-teks literasi lain seperti hukum dan lain sebagainya yaitu klaim Alkitab itu sendiri bahwa Tuhan lah penulisnya meskipun Alkitab yang terdiri dari 66 kitab ditulis lebih kurang

Distributed by the American Schools of Oriental Research. $9 \times 5 \frac{1}{2}$ in., x + 246 Pp. New Haven, 1938.,"

Bulletin of the School of Oriental and African Studies 10, no. 1 (1940).

${ }^{26}$ Brand, Draper, and England, Holman Illustrated Bible Dictionary, 220.

27 Ibid., 418.

${ }^{28}$ Gary M Burge and Andrew E Hill, The Baker Illustrated Bible Commentary (Grand Rapids, Michigan: Baker Publishing Group, 2012), 468.

${ }^{29}$ J. D. Douglas and Merrill C. Tenney, Zondervan Illustrated Bible Dictionary (Zondervan, 2009), 1377. 
Vol. 2, No. 2 (2021):65-81

http://journalsttcipanas.ac.id/index.php/NPTRS/

p-ISSN 2722-9726, e-ISSN 2722-9718

Published by Cipanas Theological Seminary

dalam rentang waktu 1500 tahun oleh penulis yang berbeda-beda. Karenanya, perlu ada pemahaman yang akurat dari apa yang dimaksudkan Alkitab. Namun demikian, dapat terjadi perbedaan pandangan terhadap apa yang dimaksud Alkitab dalam beberapa poin. Oleh karenanya, perlu dilakukan beberapa pendekatan yang berbeda dalam penafsiran melalui berbagai disiplin ilmu agar diperoleh pemahaman yang komprehensif. ${ }^{30}$

Secara garis besar ada dua persoalan utama dalam penafsiran Alkitab. Persoalan pertama adalah kebahasaan. Alkitab ditulis dalam bahasa manusia sehinggan untuk memahami harus dilakukan dengan pendekatan literasi baik dalam struktur literasinya, bentuk literasinya dan korelasi literasinya. Persoalan kedua adalah signifikansi teologis dari materi-materi yang ditafsirkan. Hal ini bertitik tolak dari karakter fundamental Alkitab itu sendiri sebagai tulisan yang diwahyukan oleh Roh Kudus, sehingga memiliki nilai dan makna teologis yang penting. Soal signifikansi teologis inilah yang tidak ditemukan dalam sastra-sastra lain. Kedua persoalan ini dapat diselesaikan melalui penafsiran yang memperhatikan definisi dari kata, analisis kontekstual, bentuk dan tipe literasi, analogi historis, dan perbedaan sintaksis. Proses penafsiran dimulai dari menemukan makna yang sebenarnya dari kata-kata dan istilah-istilah yang terdapat dalam teks-teks Alkitab. ${ }^{31}$

Berikut ini beberapa pendekatan dalam penafsiran Alkitab. Pertama adalah pendekatan leksikal yang bertujuan untuk memahami makna kata. Penafsir dituntut untuk memiliki pengetahuan tentang perkembangan secara historis dari makna kata yang sedang dipelajari. Makna kata dapat ditemukan dalam sejarahnya (secara diakronik) daripada dari penggunaannya secara konvensional dalam periode masa kini (secara sinkronik). Hal ini penting untuk menghidari 'etymological fallacy' atau kesalahan secara etimologi. Kedua adalah pendekatan sintak yang berfokus untuk memahami prinsip-prinsip grammatikal dari bahasa asli teks yang sedang ditafsirkan. Grammar berfungsi untuk menjelaskan hukum atau prinsip-prinsip dari bahasa dalam fungsinya untuk menyatakan ide-ide atau pemikiran. Pendekatan grammatical ini

\footnotetext{
${ }^{30}$ Brand, Draper, and England, Holman Illustrated Bible Dictionary, 419.

${ }^{31}$ Douglas and Tenney, Zondervan Illustrated Bible Dictionary, 1377.
} 
Vol. 2, No. 2 (2021):65-81

http://journalsttcipanas.ac.id/index.php/NPTRS/

p-ISSN 2722-9726, e-ISSN 2722-9718

Published by Cipanas Theological Seminary

penting bagi penafsir yang menggunakan bahasa yang berbeda, agar dapat memahami alur berpikir dan idiom-idiom khusus dari bahasa teks yang ditafsirkan. Ketiga adalah pendekatan secara kontekstual, yang berarti penafsir harus memperhatikan komposisi teks secara utuh. Sering kali bayangan arti diberikan terhadap suatu kata berdasarkan natur konteks dimana kata tersebut menjadi bagian darinya. Pembagian teks alkitabiah kedalam pasal dan ayat sering menjadi masalah terhadap penafsiran karena cenderung mengabaikan signifikansi konteks dan seakan-akan masing-masing ayat berdiri sendiri. Hal ini harus menjadi perhatian seorang penafsir. Keempat adalah pendekatan sejarah karena sangat penting bagi seorang penafsir untuk menemukan keadaan historis yang mengelilingi teks yang ditafsirkan. Termasuk dalam hal ini adalah adat istiadat, kebiasaan-kebiasaan dan kondisi psikologis orang-orang yang ada dalam teks yang ditafsirkan, semua ini sangat penting untuk memahami teks dengan benar. Aspek-aspek yang dipelajari yang berhubungan dengan orang-orang masa lalu termasuk metode dokumentasi sejarah, gaya berbicara (dialektika), tipe literature, dan konsep pemahaman mereka terhadap waktu atau kronologi. Hasil temuan historis baik yang bersifat umum maupun khusus dapat menolong kebutuhan seorang penafsir untuk melakukan tafsiran. Kelima adalah pendekatan analogi Kitab Suci yang artinya menggunakan Alkitab itu sendiri sebagai panduan untuk memahami Alkitab. Hal ini penting untuk memastikan bahwa tafsiran yang dihasilkan benar karena jika suatu hasil tafsiran dari suatu bagian Alkitab kontradiktif dengan tren keseluruhan Alkitab, maka bisa dipastikan bahwa hasil tafsiran tersebut salah. Alkitab akan mengkonfirmasi dirinya sendiri. Pengetahuan yang benar dan akurat dari sudut pandang alkitabiah sangat penting. Seorang penafsir harus mampu mengesampingkan prasangkanya dan membaca teks dari sudut pandang penulis aslinya. $^{32}$

Semua pendekatan ini adalah strategi yang bertujuan meningkatkan otoritas Alkitab dengan memastikan harmonisasi dan identifikasi dari dasar alkitabiah dengan penerapan sekunder. Oleh karen itu, fokus hermeneutik menghubungkan komentar eksplisit teks-teks alkitabiah, yang membedakan teks dari interpretasi dengan bantuan

\footnotetext{
32 Ibid., 1378-1379.
} 
Vol. 2, No. 2 (2021):65-81

http://journalsttcipanas.ac.id/index.php/NPTRS/

p-ISSN 2722-9726, e-ISSN 2722-9718

Published by Cipanas Theological Seminary

teknik-teknik sastra lainnya melalui revisi dan pemutakhiran di dalam kitab-kitab biblika itu sendiri seperti penulisan ulang teks-teks alkitabiah baik di dalam maupun di luar Alkitab, dan kreativitas produksi sastra yang ditata atau mengacu pada tulisantulisan biblika. Namun demikian sastra biblika membedakan dirinya sendiri dari teksteks para-biblika melalui koherensi dan keseragamannya berdasarkan tolak ukur sastra dan teologis umum maupun hermeneutika yang mendasarinya. Kitab suci dianggap sebagai penafsirnya sendiri. ${ }^{33}$

Meskipun terlihat kompleks, prosedur hermeneutik sebenarnya tidak serumit yang dibayangkan. Pertama, kenali genre literature kitab dan gunakan aturan-aturan kebahasaan yang tepat terhadap kitab tersebut. Kedua, harus mempelajari perkembangan struktural dari teks dan melihat bagaimana masing-masing bagian berhubungan terhadap keseluruhan, dengan demikian melihat perkembangan konteknya. Ketiga, penafsir harus mengidentifikasi komponen grammatical dan leksikal dari kalimat untuk menentukan kemungkinan arti dari teks. Keempat, penafsir harus menggunakan informasi tentang latarbelakang untuk menjadi jembatan antara harapan penulis terhadap pemahaman pembaca aslinya dengan dunia masa kini. Kelima, penafsir harus melihat ikatan teologis dari teks dengan bagian lain dalam kitab dan keseluruhan Alkitab. Sebagai bagian akhir, seorang penafsir harus melakukan pendekatan kritis terhadap penarikan kesimpulan, mengevaluasi kesesuaian dan kepaduan, dan membandingkan kesimpulan yang diambil dengan kesimpulan dari penafsir yang lain dalam komunitas iman orang percaya. ${ }^{34}$

\section{Implementasi Arkeologi Alkitabiah Dalam Hermeneutik Untuk Penafsiran Alkitab}

Sebagai pewahyuan dari Tuhan, Alkitab bukan sekedar kumpulan sastra kuno yang mencatat peristiwa-peristiwa penting di masa lampau, tapi juga memiliki dimensi teologis yang berperan sebagai pedoman iman dan kehidupan, khususnya bagi orang-

\footnotetext{
${ }^{33}$ Reinhard G. Kratz, Historical and Biblical Israel The History, Tradition, and Archives of Israel and Judah (Oxford, United Kingdom: Oxford University Press, 2015), 130.

${ }^{34}$ Douglas and Tenney, Zondervan Illustrated Bible Dictionary, 1379-1380.
} 
Vol. 2, No. 2 (2021):65-81

http://journalsttcipanas.ac.id/index.php/NPTRS/

p-ISSN 2722-9726, e-ISSN 2722-9718

Published by Cipanas Theological Seminary

orang Kristen masa kini. ${ }^{35}$ Peran ini akan semakin diteguhkan melalui pembuktian historis melalui penemuan-penemuan arkeologis atas peristiwa-peristiwa yang tercatat di Alkitab. ${ }^{36}$ Jadi perpektif teologis Alkitab akan semakin diteguhkan oleh perspektif saintifik dari arkeologi alkitabiah. Arkeologi alkitabiah sebagai bagian dari bidang umum, dapat didefinisikan sebagai penerapan ilmu arkeologi pada bidang studi biblika. Alkitab terdiri dari dua bagian besar. Pertama adalah Perjanjian Lama yang merupakan catatan selektif tentang sejarah suatu bangsa dan tempat dalam hubungannya dengan Allah. Kedua adalah Perjanjian Baru, yang merupakan kisah lanjutan dari Perjanjian Lama dan sejarahnya, yang mencakup bangsa-bangsa dan negeri-negeri lain, khususnya dalam hubungannya dengan Allah dalam pribadi Yesus Kristus. Sehubungan dengan perspektif ini, arkeologi alkitabiah berurusan dengan sisa-sisa real dari sejarah tempattempat dan orang-orang di dalamnya, atau memberikan referensi pada konteks alkitabiah. ${ }^{37}$

Dalam aspek pendekatan historis inilah kemudian arkeologi alkitabiah memiliki peran signifikan dalam hermeneutik sebagai metode penafsiran Alkitab secara biblika yaitu untuk dapat memahami dengan lebih baik teks yang akan ditafsirkan dengan memperoleh informasi-informasi historis yang valid melalui temuan-temuan arkeologis yang relevan dengan teks tersebut untuk dikomparasikan dengan data-data biblika dari teks. ${ }^{38}$ Berikut ilustrasi hubungan teks biblika dengan data arkeologis dalam konteks pendekatan historis. ${ }^{39}$

Gambar 1. Ilustrasi Hubungan Teks Biblika Dengan Data Arkeologis.

\footnotetext{
35 Jhon Leonardo Presley Purba, "Makna Kemah Suci Hingga Bait Allah Bagi Kehidupan Religius Kristen Masa Kini,” DANUM PAMBELUM: Jurnal Teologi dan Musik Gereja 1, no. No. 1 (2021): DPJTMG: Mei (2021): 21-36.

${ }^{36}$ Koestoro, "Arkeologi Alkitab Dalam Fungsinya Sebagai Penjelasan Dan Konfirmasi Alkitab."

${ }^{37}$ Price and House, Zondervan Handbook of Biblical Archaeology, 28.

${ }^{38}$ Randall Price and H. Wayne House, Zondervan Handbook of Biblical Archaeology (Grand Rapids, Michigan: Harper Collins Publishers, 2017), 38.

${ }^{39}$ Price and House, Zondervan Handbook of Biblical Archaeology, 40.
} 
Vol. 2, No. 2 (2021):65-81

http://journalsttcipanas.ac.id/index.php/NPTRS/

p-ISSN 2722-9726, e-ISSN 2722-9718

Published by Cipanas Theological Seminary

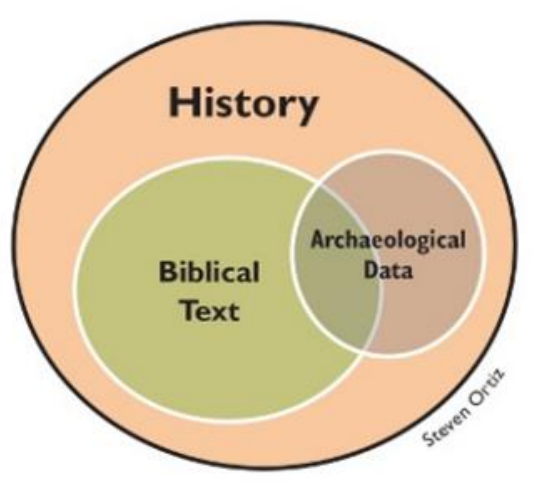

Temuan-temuan arkeologis akan memberikan informasi terhadap konteks dan latar belakang teks, tentang budaya, kebiasan, adat istiadat, bahasa dan informasiinformasi penting yang lain. Melalui informasi ini kemudian penafsir dapat melihat teks sebagaimana maksud penulis dan pemahaman pembaca asli di masa lampau. Namun demikian, hubungan komposisi Alkitab dan sifat data-data arkeologis sangat kompleks, dan karenanya harus berhati-hati dalam membuat hubungan historis antara keduanya. Penting juga untuk mengetahui bahwa ketidaklengkapan data sejarah yang tersedia dari arkeologi harus menjadi peringatan terhadap upaya untuk menggunakan data-data arkeologis untuk mengkritik informasi yang lebih lengkap, yang tersedia dalam dokumen sastra di Alkitab tentang suatu peristiwa sejarah. Karena alasan ini, tidaklah tepat untuk mengutamakan data arkeologis di atas teks-teks alkitabiah untuk menantang integritas Alkitab itu sendiri. Oleh karena itu, Alkitab sebagai dokumen sastra, harus diprioritaskan dalam penentuan akhir keakuratan dalam sejarah yang dicatatnya karena Alkitab sebagai dokumen sastra juga merupakan dokumen arkeologis. ${ }^{40}$ Bagi sejarawan, hal tersebut bersifat historis yang kemudian menganggap tradisi alkitabiah sebagai Kitab Suci yang diwahyukan oleh Tuhan, yang pada dasarnya bersifat teologis dan eksistensial. $^{41}$

Berikut ini sedikitnya lima implementasi konkrit arkeologi alkitabiah terhadap penafsiran. Pertama, mengenali kebutuhan untuk mengintegrasikan teks-teks alkitabiah

\footnotetext{
${ }^{40}$ Price and House, Zondervan Handbook of Biblical Archaeology, 38.

${ }^{41}$ Kratz, Historical and Biblical Israel The History, Tradition, and Archives of Israel and Judah, 205.
} 
Vol. 2, No. 2 (2021):65-81

http://journalsttcipanas.ac.id/index.php/NPTRS/

p-ISSN 2722-9726, e-ISSN 2722-9718

Published by Cipanas Theological Seminary

dan data arkeologis. Sebagaimana eksegesis merupakan alat untuk mengungkap makna teologis sebuah teks, ekskavasi merupakan alat untuk mengungkap konteks historis dan makna budaya sebuah teks. Karena teks-teks alkitabiah berada dalam konteks sejarah, ada kemungkinan untuk menemukan korelasi antara teks dan artefak. Misalnya, data arkeologi telah menyediakan elemen-elemen interpretatif penting untuk memahami secara holistik praktik atau terminologi yang terikat dengan budaya. Penemuan sastra papirus Aram dari Elephantine dan papirus Yunani Koine dari Mesir telah membantu interpretasi yang tepat dari praktik budaya Yahudi dan istilah teologis Perjanjian Baru. Kedua, mengembangkan pemahaman tentang cara kerja arkeologi. Untuk menggunakan data arkeologi, penafsir Alkitab perlu mengenal teknik dan terminologi arkeologi dan memiliki akses ke sumber daya teknis arkeologi misalnya, laporan lapangan, jurnal peer-review, studi khusus, database digital, dan majalah. Sejumlah majalah populer dan situs online didedikasikan untuk menampilkan penggalian arkeologi yang sedang berlangsung, melaporkan berita dari lapangan, dan menerbitkan artikel interpretatif yang menunjukkan bagaimana arkeologi berhubungan dengan teks Alkitab. Ketiga, identifikasi data arkeologis dapat mempengaruhi pemahaman teks Alkitab. Setelah teks diidentifikasi untuk menyesuaikan kontennya dengan konteks Timur Dekat, pertanyaan diagnostik interpretatif dasar (siapa, apa, kapan, di mana, bagaimana, mengapa) diajukan terhadap teks untuk mengidentifikasi sejarah, budaya, sosial, dan masalahmasalah keagamaan yang di mana jawaban-jawabannya dapat disediakan oleh data-data arkeologi. Keempat, membangun konstruksi eksegesis alkitabiah-arkeologis, di mana kedua sumber data digabungkan setelah menggunakan pemikiran kritis untuk membedakan bagaimana data arkeologi sesuai dengan data alkitabiah. Prioritas harus diberikan pada teks alkitabiah tertulis saat menggunakan arkeologi sebagai kontrol untuk konteks sejarah. Ini menghasilkan pemahaman yang lebih lengkap tentang teks dalam konteksnya. Kelima, mengajarkan hasil dari eksegesis. Dalam berkhotbah atau mengajar harus ada penjelasan tentang data arkeologi yang dipilih dan bagaimana hal itu membantu dalam memahami teks Alkitab. Manfaatnya bagi pengajar Alkitab adalah pengajaran yang lebih percaya diri dan kredibel dari teks yang diinformasikan secara 
Vol. 2, No. 2 (2021):65-81

http://journalsttcipanas.ac.id/index.php/NPTRS/

p-ISSN 2722-9726, e-ISSN 2722-9718

Published by Cipanas Theological Seminary

historis, yang menghasilkan informasi yang lebih akurat terhadap audiens untuk kemudian dapat menerapkannya lebih akurat. ${ }^{42}$

\section{Kesimpulan}

Implementasi arkeologi alkitabiah dalam metode penafsiran hermeneutik untuk mendapatkan penafsiran Alkitab yang akurat, valid, teliti dan dapat dipertanggungjawabkan yaitu sebagai alat untuk mengungkap konteks historis dan makna budaya sebuah teks dengan memahami hubungan arkeologi dengan teks Alkitab, sebagai alat untuk mengidentifikasi teks untuk menyesuaikan kontennya dengan konteks Timur Dekat Kuno melalui identifikasi sejarah, budaya, sosial, dan masalahmasalah keagamaan yang disediakan oleh data-data arkeologi, sebagai alat membangun konstruksi eksegesis alkitabiah-arkeologis dengan menggabungkan kedua sumber data tersebut melalui pemikiran kritis untuk menyesuaikan data arkeologi dengan data alkitabiah, sebagai alat kontrol untuk konteks sejarah dan alat menghasilkan informasi historis yang lebih akurat bagi pendengar agar penerapan lebih akurat.

\section{Referensi}

Archer, Gleason L. New International Encyclopedia Of Bible Difficulties. Zondervan, 2011.

Baker, David L., and John J. Bimson. Mari Mengenal Arkeologi Alkitab. Jakarta: BPK Gunung Mulia, 2011.

Barnhart, Robert K. Dictionary of Etymology. New York: Wilson Company, 1995.

Birnbaum, S. "The Haverford Symposium on Archælogy and the Bible. By W. F.

Albright, G. A. Barton, H. J. Cadbury, J. W. Flight A. Goetze, T. J. Meek, J. A.

Montgomery, J. A. Wilson, and E. Grant, Editor. Biblical and Kindred Studies, No.

6. Haverford College, Published Jointly with and Distributed by the American Schools of Oriental Research. $9 \times 5$ 1/2in., x +246 Pp. New Haven, 1938." Bulletin of the School of Oriental and African Studies 10, no. 1 (1940).

Bloesch, Donald G. Christian Foundations Holy Scripture Revelation, Inspiration and Interpretation. Illinois, USA: The Paternoster Press, 1994.

${ }^{42}$ Price and House, Zondervan Handbook of Biblical Archaeology, 40-41. 
Vol. 2, No. 2 (2021):65-81

http://journalsttcipanas.ac.id/index.php/NPTRS/

p-ISSN 2722-9726, e-ISSN 2722-9718

Published by Cipanas Theological Seminary

Blomberg, Craig \& Gaffin, Richard \& Spencer, Scott \& Wall, Robert \& Westphal, Merold. Biblical Hermeneutics: Five View. Illinois, USA: Intervarsity Press, 2012.

Brand, Chad, Charles Draper, and Archie England. Holman Illustrated Bible

Dictionary. Nashville, Tennessee: Holman Bible Publishers, 2003.

Burge, Gary M, and Andrew E Hill. The Baker Illustrated Bible Commentary. Grand Rapids, Michigan: Baker Publishing Group, 2012.

Douglas, J. D., and Merrill C. Tenney. Zondervan Illustrated Bible Dictionary.

Zondervan, 2009.

Hrytsiuta, Oksana. "Development of Studies in Biblical Archaeology in the Kyiv

Theological Academy in the Second Half of XIX Century." Materials and studies on archaeology of Sub-Carpathian and Volhynian area 23 (2019).

King, Philip J., and Lawrence E. Stager. Kehidupan Orang Israel Alkitbiah. Jakarta:

BPK Gunung Mulia, 2010.

Koestoro, Lucas Partanda. “Arkeologi Alkitab Dalam Fungsinya Sebagai Penjelasan

Dan Konfirmasi Alkitab.” Berkala Arkeologi Sangkhakala 13, no. 26 (2018).

Kratz, Reinhard G. Historical and Biblical Israel The History, Tradition, and Archives

of Israel and Judah. Oxford, United Kingdom: Oxford University Press, 2015.

Lumingkewas, Marthin Steven. El Dan Yahweh Allah Israel. Osf Prepints, 2020.

Philip, Johnson C., and Saneesh Cherian. Biblical Archeology Volume 1 Archeology

And The Christian. USA: Philip Communications, 2013.

Pratt, Richard L. He Gave Us Scripture: Foundations of Interpretation. Florida, USA:

Third Millennium Ministries, 2013.

Price, Randall, and H. Wayne House. Zondervan Handbook of Biblical Archaeology.

Grand Rapids, Michigan: Harper Collins Publishers, 2017.

Price, Randall, and Wyne House. Zondervan Handbook of Biblical Archaeology. Grand Rapids Michigan, USA: World of the Bible Ministries, Inc, 2017.

Purba, Jhon Leonardo Presley. "Makna Kemah Suci Hingga Bait Allah Bagi Kehidupan Religius Kristen Masa Kini.” DANUM PAMBELUM: Jurnal Teologi dan Musik Gereja 1, no. No. 1 (2021): DPJTMG: Mei (2021): 21-36. 


\section{The New Perspective in Theology and Religious Studies}

Vol. 2, No. 2 (2021):65-81

http://journalsttcipanas.ac.id/index.php/NPTRS/

p-ISSN 2722-9726, e-ISSN 2722-9718

Published by Cipanas Theological Seminary

Purba, Jhon Leonardo Presley, and Robinson Rimun. "Kritik Terhadap Metode Tafsir Hermeneutik Pembebasan Terhadap Peristiwa Keluaran Sebagai Suatu Bentuk Pembebasan.” Jurnal Teologi Amreta 4, no. 2 (2021).

http://ojs.sttsati.ac.id/index.php/amreta/article/view/54.

Seger, Joe D., and P. R. S. Moorey. “A Century of Biblical Archaeology.” Journal of the American Oriental Society 115, no. 4 (1995).

Sharon, Ilan. "Biblical Archeology.” In Encyclopedia of Archaeology, 2008.

Zaluchu, Sonny Eli. "Metode Penelitian Di Dalam Manuskrip Jurnal Ilmiah Keagamaan.” Jurnal Teologi Berita Hidup 3, no. 2 (2021).

Zondervan. NIV Cultural Backgrounds Study Bible Bringing to Life the Ancient World of Scripture. Grand Rapids Michigan, USA: Zondervan, 2016. 